\title{
Lattice Strain of Zn-Mn Mixed Ferrite Nanocrystals in a Core-Shell Morpho-Chemical Structure
}

\author{
F. H. Martins ${ }^{a, b} *$ (D), V.Pilati ${ }^{a, c}$, F.L.O. Paula ${ }^{a, b}$, R.C. Gomes ${ }^{d}$, R. Perzynski ${ }^{b}$, J. Depeyrot ${ }^{a}$ \\ aniversidade de Brasília (UnB), Instituto de Física, Grupo de Fluidos Complexos, 70919-970, \\ Brasilia, DF, Brasil. \\ ${ }^{b}$ Sorbonne Université CNRS, Laboratoire PHENIX, UMR 8432, 4, Place Jussieu, 75005, Paris, France. \\ ${ }^{c}$ Universidade de Brasília (UnB), Laboratório de Nanociência Ambiental e Aplicada, \\ Brasília, DF, Brasil. \\ ${ }^{d}$ Universidade Federal de Santa Catarina (UFSC), Departamento de Física, 88040-900, \\ Florianópolis, SC, Brasil.
}

Received: November 23, 2021; Revised: January 31, 2022; Accepted: February 03, 2022

In this work, the crystalline structure, chemical composition, size, and morphology of core@shell nanoparticles based on $\mathrm{Zn}-\mathrm{Mn}$ ferrite nanocrystals were investigated. These materials have been proposed as promising candidates for multifunctional applications in biomedicine, catalysis, environmental remediation, among others. Those properties were probed by using several experimental techniques such as Synchrotron X-Ray Diffraction, Energy-Dispersive X-ray Spectroscopy, Transmission Electron Microscopy and Selected Area Electron Diffraction. Results show that all synthesized nanoparticles present a single crystalline spinel phase without the appearance of undesirable byproducts. The nanoparticles present a non-stoichiometric $\mathrm{Zn}-\mathrm{Mn}$ ferrite core, due to a Fe enrichment and a $\mathrm{Zn}$ loss with respect to the synthesis medium. The surface treatment of the nanoparticles induces a greater iron enrichment, which occurs at the nanoparticles surface without changing the crystalline structure. Finally, modifications in lattice parameters and strain suggest a contribution of the $\mathrm{Mn}^{2+}$ cations, mainly related to their easy oxidation in the synthesis route, which increases the structural vacancies of Mn-richer ferrites.

Keywords: Strain, Mixed ferrite, Nanocrystals, Core-Shell, Nanoparticles.

\section{Introduction}

Nanoparticles (NPs) based on iron-oxides nanocrystals have been probed as multifunctional tools for several applications in the biomedical field ${ }^{1-5}$, agriculture ${ }^{6-8}$, environmental remediation $^{9-12}$, catalysis $^{13-15}$, among others. These applications are conceived through the design of physical properties, which can be achieved by performing adjustments on the chemical composition of the ferrites, modifying physical properties such as the size of the nanocrystals, crystalline structure, and cation distribution.

Doped ferrites NPs have been prepared and investigated by many authors due to opportunity of modulating their size and morphology ${ }^{16-18}$, structural ${ }^{13,14,19-22}$, dielectric ${ }^{23,24}$ and magnetic properties ${ }^{25-29}$ by chemical composition of the NPs and the synthetic route. They have been prepared by several techniques including hydrothermal coprecipitation ${ }^{17,18,30}$, polyol synthesis ${ }^{13}$, thermal decomposition ${ }^{26,31}$, combustion method $^{19}$, sol-gel auto-combustion method ${ }^{25,32}$, among others.

Ferrite nanocrystals doped with $\mathrm{Zn}$ are a good example of multifunctional nanomaterials, with highly adjustable properties through the $\mathrm{Zn}$ content incorporated into the crystalline structure ${ }^{33}$. For instance, the introduction of non-magnetic $\mathrm{Zn}^{2+}$ ions into the crystalline structure of $\mathrm{Mn}$

*e-mail: nandofisunb@gmail.com and Co ferrites leads to modifications in thermomagnetic properties $^{18}$, with a reduction of Curie temperature ${ }^{18,34-36}$. This feature is promising to achieve a temperature self-regulating approach in magnetic hyperthermia applications ${ }^{18,37,38}$.

Nanoparticles can be coated/functionalized by using different compounds, including biocompatible polymeric molecules ${ }^{4,39-41}$, as well as additional layers of inorganic materials, such as metallic oxides ${ }^{18,42,43}$, both aiming to enhance their properties and applications ${ }^{42,44,45}$. Besides its functionalization, the coating of magnetic nanoparticles with polymers and/or a surface charge density makes it possible to obtain magnetic fluids with colloidal stability, preventing NPs from aggregation. For instance, the strategy of covering $M \mathrm{Fe}_{2} \mathrm{O}_{4}$ ferrite nanoparticles ( $M$ being a divalent d-block metal, such as $\mathrm{Mn}^{2+}, \mathrm{Fe}^{2+}, \mathrm{Co}^{2+}, \mathrm{Ni}^{2+}, \mathrm{Cu}^{2+}, \mathrm{Zn}^{2+}$ ) with a maghemite shell $\left(\gamma-\mathrm{Fe}_{2} \mathrm{O}_{3}\right)$ has been used to achieve greater chemical stability of NPs in acidic medium, preventing the NPs chemical dissolution due to the acidic attack ${ }^{46}$. This approach makes it possible to disperse NPs in aqueous media with acidic $\mathrm{pH}$, leading to electric double-layer magnetic fluids (EDL-MF) ${ }^{46-48}$, and also modifies the magnetic and structural properties of the nanoparticles. In fact, such NPs are usually described in a core@shell framework ${ }^{18,49}$, where the physical properties are resulting from both core and shell structures, as well as the interface between them. In the case 
of bi-magnetic core@shell nanoparticles (CS-NPs), it is possible to combine different magnetic phases in order to emphasize their global magnetic behavior ${ }^{43,45,50,51}$. Hence, a profound knowledge of their structural properties is imperative and has raised a lot of interest in the nanotechnology field in the past years.

In this paper, we investigate the structure and morphological properties of colloidal NPs based on Zn-doped Mn ferrites covered by a thin maghemite shell. Such NPs are known as promising nano-heaters in magnetic hyperthermia ${ }^{18}$. The colloidal stability in such aqueous dispersions is obtained thanks to an electrostatic potential induced by a NP charge density which is shielded by counterions in the medium ${ }^{52,53}$. However, the resulting core@shell structure leads to modifications in structural, morphological, and physical properties of the NPs. Then, we investigate such colloidal nanocrystals by using several electronic microscopy and synchrotron radiation techniques, such as local energy-dispersive $\mathrm{X}$-ray spectroscopy, X-ray diffraction, transmission electron microscopy, and electron diffraction.

Hereafter we first present the materials and methods used in the present work, before to describe and discuss the obtained results and analyze the structural evolution of the bare and of the core@shell NPs with the introduced $\mathrm{Zn}$ content.

\section{Materials and Methods}

\subsection{Chemical synthesis and chemical analysis}

In this work we consider bi-magnetic core@shell nanoparticles (CS-NPs) based on Zn-doped Mn ferrites cores covered by a maghemite shell, presenting a chemical composition portrayed as $\mathrm{Zn}_{\mathrm{y}} \mathrm{Mn}_{(1-\mathrm{y})} \mathrm{Fe}_{2} \mathrm{O}_{4} @ \gamma-\mathrm{Fe}_{2} \mathrm{O}_{3}$ (where $\mathrm{y}$ is the $\mathrm{Zn}$ content). Such NPs are obtained by a two-step synthesis procedure, which consists in an hydrothermal co-precipitation route followed by a surface treatment, that can be described as follows:

- $\quad$ First, $\mathrm{Zn}_{\mathrm{y}} \mathrm{Mn}_{(1-\mathrm{y})} \mathrm{Fe}_{2} \mathrm{O}_{4}$ nanocrystals are obtained from the polycondensation reaction of a mixture of $\mathrm{Fe}^{3+}, \mathrm{Zn}^{2+}$, and $\mathrm{Mn}^{2+}$ cations $(0.5 \mathrm{~mol} / \mathrm{L}$ aqueous solutions) in a sodium hydroxide $(\mathrm{NaOH}-2 \mathrm{~mol} / \mathrm{L})$ at boiling point $\left(\sim 100^{\circ} \mathrm{C}\right)$ and constant stirring. The imposed cations $\mathrm{Zn}: \mathrm{Mn}: \mathrm{Fe}$ volume proportion was $y:(1-y): 2$ where y is the zinc content and it varies from 0.1 to 0.9 , leading to samples named as ZM1 to ZM9, respectively.

- $\quad$ The core@shell structure arises from the surface treatment procedure, which is divided into two other steps. First, the magnetic precipitate is washed with nitric acid $\left(\mathrm{HNO}_{3}-2 \mathrm{~mol} / \mathrm{L}\right)$ to inverse the surface charge of the NPs. Then, a hydrothermal surface treatment is carried out with ferric nitrate $\left(\mathrm{Fe}\left(\mathrm{NO}_{3}\right)_{3}-0.5 \mathrm{~mol} / \mathrm{L}\right)$ to incorporate $\mathrm{Fe}^{3+}$ ions into the NPs surface. Such procedure induces a thin maghemite shell that covers the mixed-ferrite core. After the surface treatment, the NPs were dispersed in aqueous media with $\mathrm{pH} \sim 2$ after a fine adjustment of ionic strength and $\mathrm{pH}$, leading to EDL-MF with long-term colloidal stability ${ }^{52}$.
All chemicals we used in this study were of analytical grade and were used without further purification. They were: iron(III) chloride hexahydrate $\left(\mathrm{FeCl}_{3} \cdot 6 \mathrm{H}_{2} \mathrm{O} \geq 98 \%\right)$, iron(III) nitrate nonahydrate $\left(\mathrm{Fe}\left(\mathrm{NO}_{3}\right)_{3} \cdot 9 \mathrm{H}_{2} \mathrm{O} \geq 98 \%\right)$, manganese(II) chloride tetrahydrate $\left(\mathrm{MnCl}_{2} \cdot 4 \mathrm{H}_{2} \mathrm{O} \geq 98 \%\right)$, zinc(II) chloride anhydrous $\left(\mathrm{ZnCl}_{2} \geq 98 \%\right)$, sodium hydroxide $(\mathrm{NaOH} \geq 97 \%)$, and nitric acid $\left(\mathrm{HNO}_{3}>65 \%\right)$, both purchased from Sigma-Aldrich. All solutions were prepared by using deionized type I water.

The chemical composition of the NPs is investigated by the determination of $\mathrm{Zn}, \mathrm{Mn}$, and Fe fractions in each synthesis step, by using energy-dispersive X-ray spectroscopy (EDX). Measurements are obtained with a Shimadzu EDX 720 HS Spectrometer. In addition, magnetic fluids are also investigated with Flame Atomic Absorption Spectroscopy (AAS) using a Thermo Scientific Spectrometer model S series AA. In this case, specific lines are chosen for each metal to avoid any interference effects: Fe $(248.3 \mathrm{~nm} / 372.0 \mathrm{~nm})$, $\mathrm{Mn}(279.5 \mathrm{~nm})$, and $\mathrm{Zn}(213.9 \mathrm{~nm})$. Both measurements are performed at Universidade de Brasília (UnB).

\subsection{X-ray powder diffraction measurements}

All samples, bare-core NPs and CS-NPs, are probed by $\mathrm{X}$-ray diffraction (XRD) to follow the structural modifications resulting from the substitution of $\mathrm{Mn}$ cations to $\mathrm{Zn}$ ones. The measurements are carried out in powder form, which is obtained after the evaporation of the liquid phase (solvent) of magnetic fluids. The experimental data are collected at D12A-XRD1 beamline of Brazilian Synchrotron Light Source, with a monochromatic beam with $6.99 \mathrm{keV}(\lambda=1.77155 \AA)$ in the $2 \theta$ range of $15^{\circ}-120^{\circ}$, at room temperature, with an approximate area of $3 \mathrm{~mm}^{2}$. Diffraction patterns are obtained typically within intervals scanned with an angle step of $0.1^{\circ}$. In addition, in the case of ZM2, ZM5, and ZM8 samples, $\mathrm{XRD}$ is also performed right after the coprecipitation step (before the surface treatment). In this case, measurements are performed using a D8 Focus (Bruker) diffractometer $\left(\mathrm{Cu}-\mathrm{K} \alpha_{\mathrm{av}}\right.$ radiation with $\left.\lambda=1.54184 \AA\right)$ in the $2 \theta$ range of $20^{\circ}-80^{\circ}$, installed at UnB.

The lattice parameter $\langle a\rangle$, and the interplanar distances are obtained from Bragg's law and compared with the bulk standard data presented by the International Centre for Diffraction Data (ICDD no. 98-002-8512 to -8516). The crystalline diameter $D_{r x}^{S c h}$ of the CS-NPs is estimated by applying Scherrer's formula $D_{x r}^{S c h}=0.9 \lambda / \beta \cos \theta$ to the most intense peak, $\lambda$ being the X-ray wavelength and $\beta$ the full width at half of the maximum intensity (FWHM) of the most intense diffraction peak (311) - the intrinsic width is discounted using a Si standard. In addition, the volume-weighted crystallite size $D_{x r}^{W H}$ is also determined using the method proposed by Williamson \& Hall (WH $)^{54}$, applying the formula $\beta_{h k l} \cos \theta_{h k l}=0.9 \lambda / D_{x r}^{W H}+4 \varepsilon \sin \theta_{h k l}$, $\beta_{h k l}$ being the line broadening for each Bragg plane and $\varepsilon$ the deformation induced in powders due to the crystal's imperfection and distortions, so-called strain. Diffraction lines are then fitted by using a Pseudo-Voigt function ${ }^{55,56}$ and therefore the broadening is corrected by using the equation $\beta=\left(\left(\beta_{0}-\beta_{i}\right) \sqrt{\left(\beta_{0}^{2}-\beta_{i}^{2}\right)}\right)^{1 / 2}$, with $\beta_{i}$ and $\beta_{0}$ the instrumental and the measured contributions, respectively. The determination 
of the mean size of the nanoparticles by using WH method was also adopted by other authors ${ }^{57}$.

\subsection{High-Resolution transmission electron microscopy and specific area electron diffraction measurement}

Transmission Electron Microscopy and High-Resolution Transmission Electron Microscopy (TEM/HRTEM) images of the synthesized NPs are acquired by using a JEOL JEM2010 C microscope operated at $200 \mathrm{kV}$ with $\lambda=0.025 \AA$. By performing some optical changes on the device, it is possible to obtain high-resolution images highlighting the reciprocal plans of the samples. The measurements are obtained at the Plateforme de Microscopie Électronique en Transmission de la Faculté des Sciences, Campus Pierre et Marie Curie, Sorbonne Université - (SU). All samples are prepared by using the same standard procedure: a drop of diluted ferrofluid is deposited on a small copper grid covered by carbon, with a zone of approximately $3 \mathrm{~mm}^{2}$. After total evaporation of the liquid, a thin layer of NPs (usually less than $100 \mathrm{~nm}$ thick) is formed over the substrate. Then, the sample is subjected to microscopy, and the obtained micrographs are analyzed using Image $^{\circ}$ software. After TEM images are collected, we select a specific area of the micrograph of each sample to perform the electron diffraction measurements, obtaining a bi-dimensional ring pattern. Each ring is related to a family of crystallographic plans of the sample that scatters the incident beam. We used Diffraction Ring Profiler ${ }^{\circ}$ software $^{58}$ to investigate the obtained 2D patterns. Therefore, we obtain electron diffraction spectra, and we determine the inter-planar distances and index the rings by comparing the inter-planar distances with ICDD data.

\section{Results and Discussion}

\subsection{Chemical characterization of CS-NPs based on mixed ferrites cores}

We synthesized CS-NPs based on mixed Zn-Mn ferrites cores, with different $\mathrm{Zn} / \mathrm{Mn}$ proportions, covered by a maghemite shell. The NP's core stoichiometry is determined from $\mathrm{Zn}, \mathrm{Mn}$, and Fe concentrations, obtained by EDX measurements, and by considering the ferrite electroneutrality ${ }^{18}$. As discussed ahead, two mechanisms contribute to an excess of positive charges in our ferrite NPs. In brief, a $\mathrm{Zn}^{2+}$ fraction being replaced by $\mathrm{Fe}^{3+}$ cations and the oxidation of $\mathrm{Mn}^{2+}$ cations in $\mathrm{Mn}^{3+}$ or $\mathrm{Mn}^{4+}$, which commonly occurs during synthesis in alkaline medium due to the high concentration of oxygen in the medium ${ }^{59-63}$, both contribute to the ferrite oxidation. In a previous paper, we used X-ray absorption spectroscopy technique to investigate the local structure of Mn-ferrite based core@shell NPs synthesized by using the same chemical procedure as the one used here ${ }^{59}$. We found a Mn mean valence of 2.9 in bare NPs instead of 2 as first expected. Then, here we determine the stoichiometry of NP's core by using a similar valence value, assuming the chemical formula $\mathrm{Zn}^{2+}{ }_{\mathrm{y}} \mathrm{Mn}^{2.9+}{ }_{\mathrm{z}} \mathrm{Fe}^{3+}{ }_{(3-\mathrm{y}-\mathrm{z})} \mathrm{O}^{2-}{ }_{4+\delta}(\mathrm{y}$ and $\mathrm{z}$ being the real $\mathrm{Zn}$ and $\mathrm{Mn}$ content, respectively, and $\delta$ is an oxidation parameter used to balance the extra electropositive charge per formula unit - see Table 1 for the denomination of the various $\mathrm{ZM}_{\text {i }}$ samples). However, the oxidation in nanomaterials usually occurs in high pressure/temperature pathways ${ }^{64}$, which is not our case here. Thus, the excess oxygen represents cationic vacancies randomly distributed in the spinel structure and the stoichiometry is therefore renormalized considering a close-packed arrangement of 32 oxygen anions ${ }^{18}$.

By using EDX results we also calculate the fraction of $\mathrm{Zn}^{2+}$ and $\mathrm{Mn}^{2+}$ into the ferrite $\chi_{M}=([\mathrm{Mn}]+[\mathrm{Zn}]) /([\mathrm{Fe}]+[\mathrm{Mn}]+[\mathrm{Zn}])$ at all synthesis steps. The results are depicted in Figure 1. Right after the coprecipitation step (bare NPs), we obtain $\chi_{M}$ values lower than that of stoichiometric $\mathrm{MFe}_{2} \mathrm{O}_{4}$ ferrite (see Figure 1), which is equal to 0.333 . This is caused by a $\mathrm{Zn}^{2+}$ loss and a $\mathrm{Fe}^{3+}$ enrichment during the coprecipitation. This effect is enhanced as the $\mathrm{Zn}$ content increases, and is resulting from the strong alkaline $\mathrm{pH}$ of coprecipitation ${ }^{18}$. After the hydrothermal surface treatment with ferric nitrate, $\chi_{M}$ diminishes even more, emphasizing the $\mathrm{Fe}^{3+}$ incorporation into the NPs surface, and therefore leading to the core@shell structure. Indeed, in previous studies ${ }^{18,52}$, the core@shell morpho-chemical structure of the ZM5 sample has been proven by using Scanning Transmission Electron Microscope (STEM) with an EDX analyzer, which quantified the chemical composition of both core and shell phases of the NPs. In addition, the surface treatment procedure also

Table 1. Characteristics of the CS-NPs based on mixed Zn-Mn ferrites. stoichiometry of NPs' core (before surface-treatment), $\delta$ is the oxidation parameter, $\Phi_{s} / \Phi$ is the volume ratio of the shell and the whole particle after surface treatment, $t_{s h}$ is the thickness of the surface layer (shell), $D_{x r}{ }^{W H}$ and $\varepsilon$ are the XRD crystalline diameter and lattice strain, both obtained from Williamson-Hall plot, $D_{T E M}$ is TEM characteristic diameters, and $\sigma$ is the polydispersity index.

\begin{tabular}{|c|c|c|c|c|c|c|c|c|}
\hline Sample & $\begin{array}{c}\text { Core } \\
\text { Stoichiometry }\end{array}$ & $\delta^{\#}$ & $\Phi_{s} / \Phi_{(\%)}$ & $t_{s h}(\mathrm{~nm})$ & $D_{\mathrm{xr}}{ }^{\mathrm{WH}}(\mathrm{nm})$ & $\varepsilon\left(\mathrm{x} 10^{-3}\right)$ & $D_{T E M}^{\#}(\mathrm{~nm})$ & $\sigma^{\#}$ \\
\hline ZM1 & $\mathrm{Zn}_{010} \mathrm{Mn}_{081} \mathrm{Fe}_{1.82} \mathrm{O}_{4}$ & $0.40(1)$ & - & - & $43.6(5)$ & 3.7 & $16.1(5)$ & $0.46(3)$ \\
\hline ZM2 & $\mathrm{Zn}_{0,17} \mathrm{Mn}_{0,681} \mathrm{Fe}_{1,90} \mathrm{O}_{4}$ & $0.37(1)$ & 17.3 & $0.47(1)$ & 19.3(3) & 2.8 & $9.2(1)$ & $0.30(1)$ \\
\hline ZM3 & $\mathrm{Zn}_{0.23} \mathrm{Mn}_{0.61} \mathrm{Fe}_{1.33} \mathrm{O}_{4}$ & $0.34(1)$ & 25.5 & $0.57(1)$ & $11.3(4)$ & 1.6 & $8.8(2)$ & $0.39(2)$ \\
\hline ZM4 & $\mathrm{Zn}_{0,31} \mathrm{Mn}_{0.52} \mathrm{Fe}_{1.95} \mathrm{O}_{4}$ & $0.30(1)$ & 29.6 & $0.61(1)$ & $9.9(4)$ & 0.4 & $6.2(1)$ & $0.38(2)$ \\
\hline ZM5 & $\mathrm{Zn}_{0,31} \mathrm{Mn}_{0,47} \mathrm{Fe}_{2.01} \mathrm{O}_{4}$ & $0.31(1)$ & 22.5 & $0.47(1)$ & $9.3(3)$ & 0.1 & $7.4(1)$ & $0.35(1)$ \\
\hline ZM6 & $\mathrm{Zn}_{0,42} \mathrm{Mn}_{0,37} \mathrm{Fe}_{2,04} \mathrm{O}_{4}$ & $0.24(1)$ & 28.6 & $0.49(1)$ & $8.1(4)$ & 0.5 & $5.9(1)$ & $0.38(1)$ \\
\hline ZM7 & $\mathrm{Zn}_{0,39} \mathrm{Mn}_{0,30} \mathrm{Fe}_{2,13} \mathrm{O}_{4}$ & $0.26(1)$ & 27.7 & $0.52(1)$ & $9.7(3)$ & 0.6 & $4.5(1)$ & $0.36(1)$ \\
\hline ZM8 & $\mathrm{Zn}_{0,64} \mathrm{Mn}_{0,18} \mathrm{Fe}_{2,07} \mathrm{O}_{4}$ & $0.15(1)$ & 42.6 & $0.83(1)$ & $9.8(3)$ & 0.8 & $4.9(1)$ & $0.32(1)$ \\
\hline ZM9 & $\mathrm{Zn}_{0.62} \mathrm{Mn}_{0.10} \mathrm{Fe}_{2,16} \mathrm{O}_{4}$ & $0.17(1)$ & 43.6 & $0.73(1)$ & $7.5(3)$ & 0.1 & $5.3(1)$ & $0.41(1)$ \\
\hline
\end{tabular}


induces the removal of mis-coordinated divalent cations from the surface, which also contribute to the reduction of $\chi_{M}{ }^{49}$.

From AAS measurements of dispersed CS-NPs in aqueous media (EDL-MF) we determined the volume ratio of the shell and of the whole CS-NP $(\Phi / \Phi)$ and the thickness of the maghemite layer (e). Calculations were made by using a core@shell model ${ }^{49}$ for non-stoichiometric cores and considering previously estimated density values for the correspondent ferrites ${ }^{18}$.

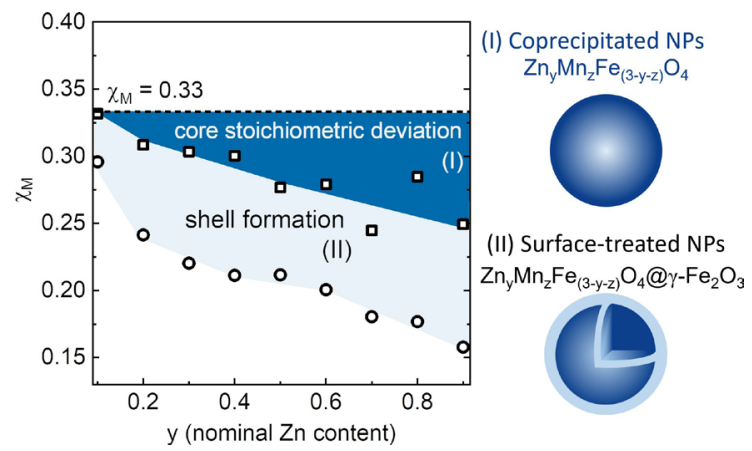

Figure 1. Fraction of $\mathrm{Zn}$ and $\mathrm{Mn}$ metals into the NPs structure, deduced from EDX measurements, as a function of nominal $\mathrm{Zn}$ content. (I) First, in the dark blue region, right after the coprecipitation, the reduction in $\chi_{M}$ (open square symbols) is related to a $\mathrm{Zn}$ loss and Fe enrichment into the NP's core structure, and (II) in the light blue region after the surface treatment, the $\chi_{M}$ reduction (open circle symbols) is related to the maghemite shell formation.

\subsection{Morphological characterization of CS-NPS}

Figure 2 depicts TEM images of representative CS-NPs samples (ZM4 and ZM7). A first look at TEM micrographs (Figures 2A, 2B, 2C, and 2D) allows us to conclude that most of the particles are approximately round and homogeneous, i.e., the particles do not present holes or discontinuities. In addition, the absence of subproducts from the synthesis steps corroborates the results which are obtained from X-ray diffractogram analysis, as we discuss in next section. Also, we observe that the particles present a strong tendency to aggregate, which is due to magnetic dipolar interactions between them ${ }^{52,65}$.

For all samples investigated, we measure the diameter of $\sim 600$ non aggregated NPs to obtain its size distribution. The obtained histograms (see Figures $2 \mathrm{E}$ and $2 \mathrm{~F}$ ) present a size distribution profile well-fitted by a log-normal probability function $P(D)=\frac{1}{\sqrt{2 \pi} D \sigma} \exp \left(\frac{-\ln ^{2}\left(D / D_{0}\right)}{2 \sigma^{2}}\right), D_{0}$ and $\sigma$ being the characteristic diameter and the standard deviation of the diameter logarithm (polydispersity), respectively. The obtained characteristic TEM diameters $D_{T E M}=D_{0}$ and polydispersity index $\sigma$ are presented in Table 1 . We find that the characteristic diameter of the particles is dependent on $\mathrm{Zn}$ content in the structure of NPs.

\subsection{Crystalline structure of CS-NPS}

The X-ray diffractograms of CS-NPs of representative samples are shown in Figures $3 \mathrm{~A}$ and 3B. All samples
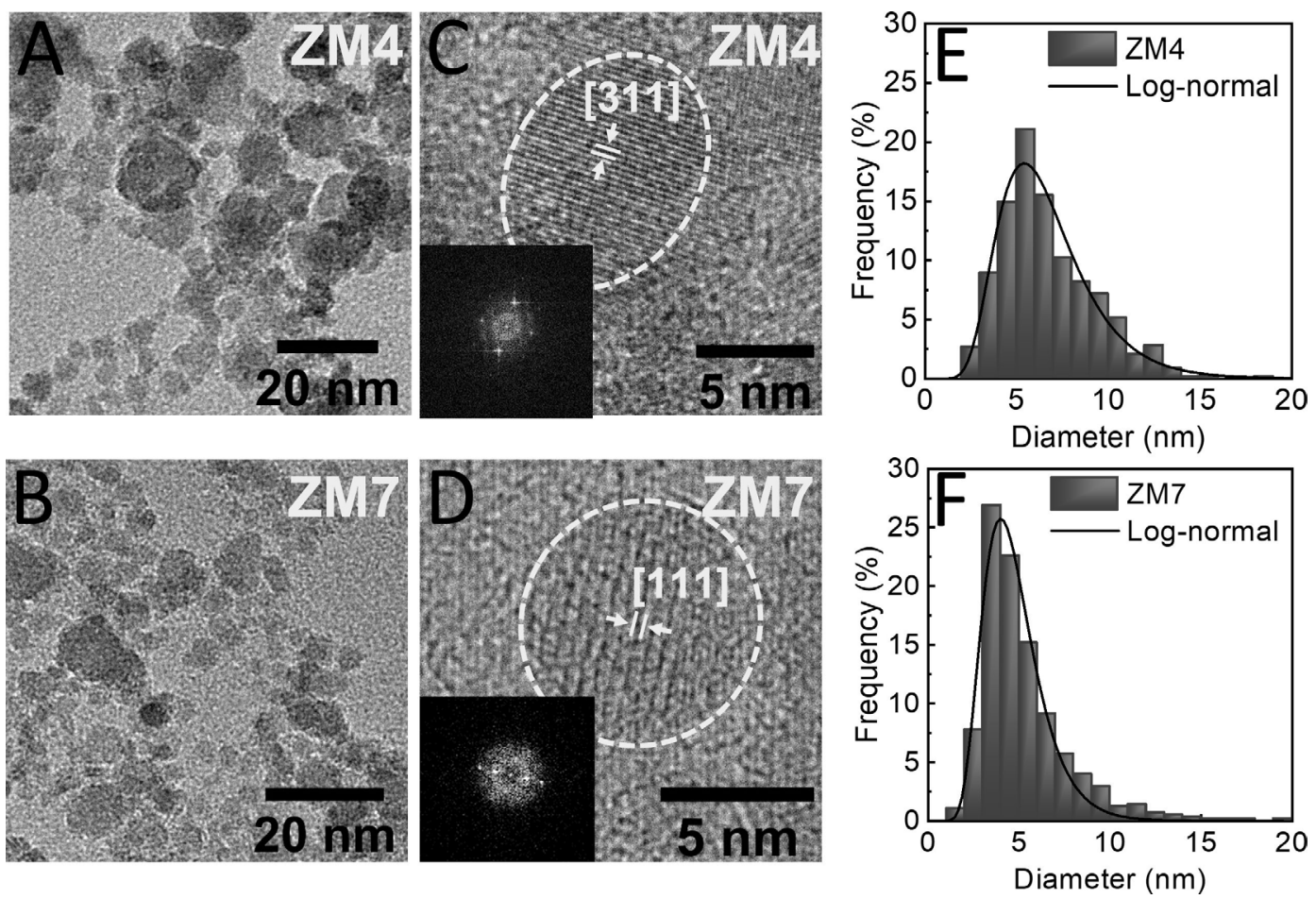

Figure 2. A and B - TEM micrographs for CS-NPs samples (ZM4 and ZM7, respectively). C and D - HRTEM of a representative NP from ZM4 and ZM7 samples. In both C and D figures, the inset depicts the FFT analysis and the correspondent identification of the crystallographic plane. E and F figures present the size distribution histograms of ZM4 and ZM7 CS-NPs, both well fitted by a log-normal probability function. 
we investigated presented similar spectra. The diffraction peaks are broad, which is due to the nanometric size of the analyzed materials. Using Bragg's law and the cubic symmetry equation it is possible to index the diffraction peaks, and then comparing the results with ICDD data, it is possible to conclude that the structure of our nanocrystals corresponds to a pure cubic spinel structure. Moreover, direct analysis of Figure 3A allows us to conclude that the progressive substitution of $\mathrm{Mn}$ cations to $\mathrm{Zn}$ ones does not provoke changes in the structure of the material, and there is no occurrence of peaks that do not correspond to the Jacobsite structure, i.e., as the $\mathrm{Zn}$ cations are added, they are incorporated in the structure of the ferrite. Before the surface treatment procedure (bare NPs), we observe a similar diffraction profile, without the presence of secondary crystalline phases (see Figure 3A).

The crystallinity of our CS-NPs is also verified by SAED in TEM measurements (see Figure 3C, 3D, and 3E for a representative sample). The electronic diffractograms (see Figure 3D) resulting from the processing of the twodimensional patterns (Figure 3C) present a $q$ dependence (wave vector), where the peak positions are related to the interplanar distances $\left(d_{h k l}\right)$. We observe that peaks are in the same positions, suggesting that all samples have similar symmetry and structure, which correspond to spinel structure following XRD data.

A quantitative analysis of the X-ray diffractograms allows us to extract information about the crystalline diameter of the nanoparticles and the lattice parameter (results in Figures 4). The former is related to the width of the diffraction peak, while the latter to the Bragg angle of the reflection peak (and therefore, interatomic distances). However, an inhomogeneous strain can also lead to an enlargement of the powder diffraction lines. Thus, we used WH plots to deconvolute such contributions (see Figure 4B). The results are depicted in Figures 4A, 4B and 4C.
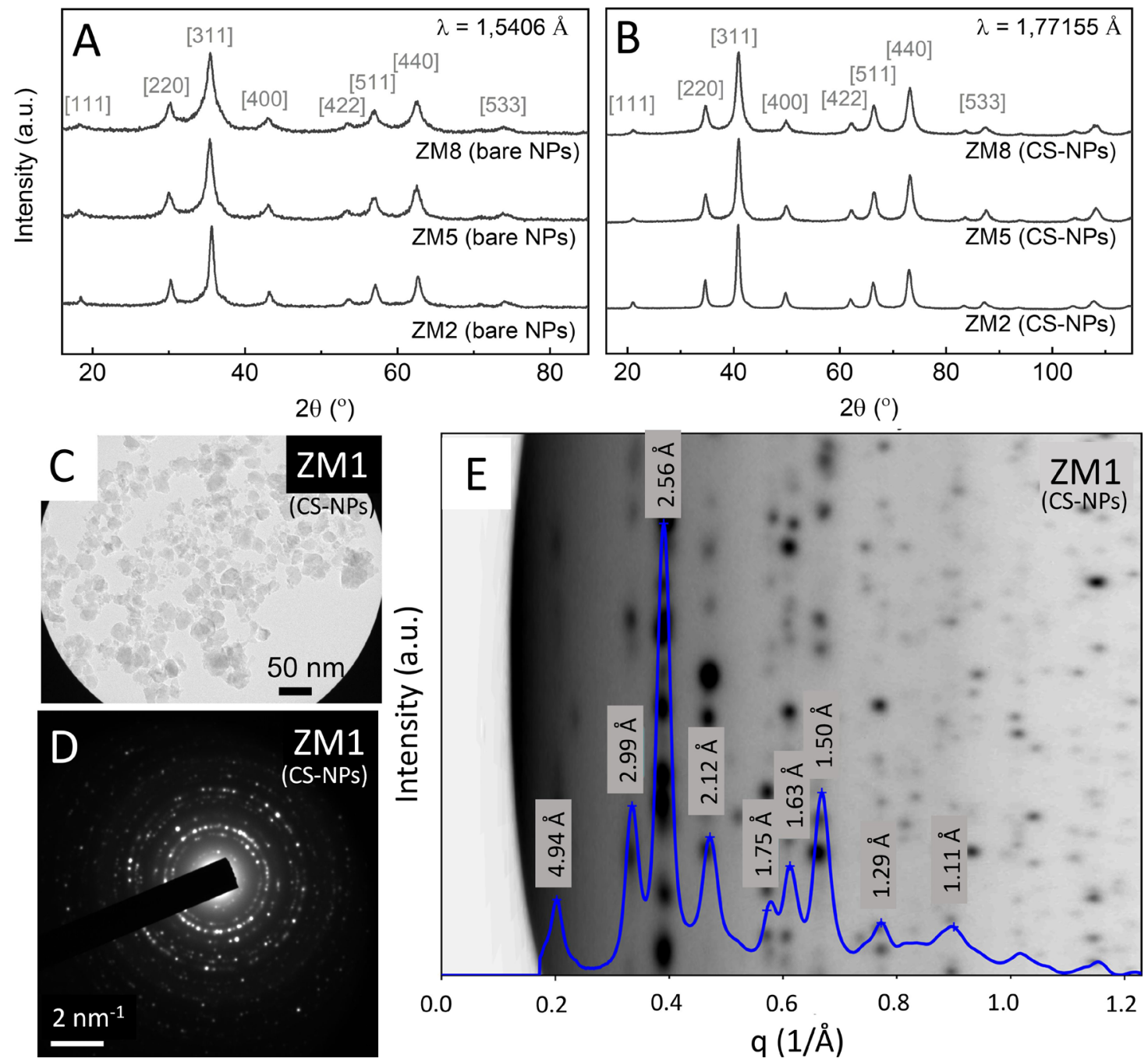

Figure 3. A. X-ray diffractograms of representative CS-NPs based on Zn-Mn mixed ferrite right after the coprecipitation (bare NPs) and B. after the surface treatment (CS-NPs). All samples presented similar spectra with a single crystalline phase. C. Selected area to perform the electron diffraction measurements of ZM1 sample, D. 2D pattern obtained from electron diffraction measurement of the specific area selected at D; and E. resulting electron diffractogram. 


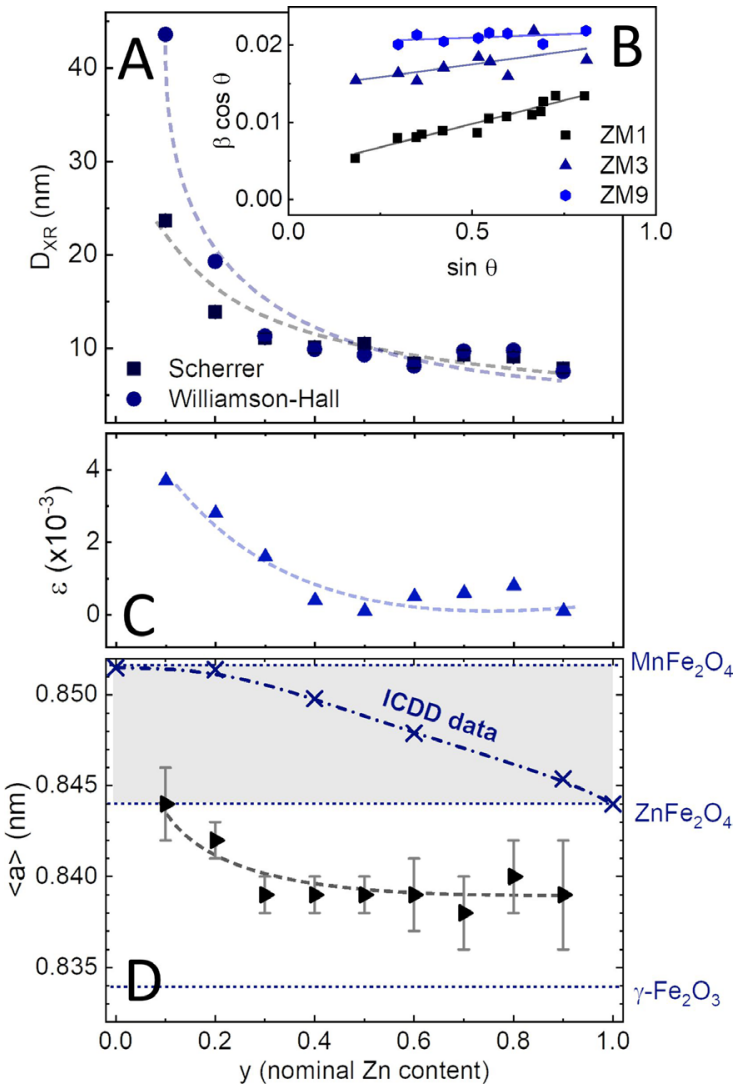

Figure 4. Results from XRD analysis as a function of nominal Zn content (y): A: Crystalline diameter of CS-NPs obtained from Scherrer equation (dark squares) and Williamson-Hall (WH) plot (blue circles); Inset (B): WH plots for some representative CS-NPs samples. C: lattice strain obtained from WH plot. D: Lattice parameters of CS-NPs with mixed ferrite cores. Blue cross-shaped marks dots and dotted lines correspond to ICDD data from stoichiometric bulk $\mathrm{MnFe}_{2} \mathrm{O}_{4}$ and $\mathrm{ZnFe}_{2} \mathrm{O}_{4}$ ferrites and bulk maghemite $\gamma-\mathrm{Fe}_{2} \mathrm{O}_{3}$.

Results show a decrease in crystalline diameter with increasing Zn content in the ferrite structure (see Figure 4A). This is due to a preference in the nucleation process over crystalline growth during the coprecipitation of $\mathrm{Zn}$-richer ferrites, which was also reported by other authors ${ }^{34,66}$. Indeed, according to nucleation theory, the different nature of divalent-metals synthesis precursors leads to modifications in the thermodynamics involved in the condensation of nanoparticles ${ }^{67,68}$. In addition, in the case of $\mathrm{Zn}$ - and $\mathrm{Zn}$-doped ferrites, even on nanoscale, the strong preference of $\mathrm{Zn}^{2+}$ for the tetrahedral sites of the spinel structure due to its $3 \mathrm{~d}^{10}$ electronic configuration may also contribute to reducing the crystalline diameter, since the crystalline growth depends on the availability of the tetrahedral sites ${ }^{69}$.

Concerning the lattice strain obtained from the WH plots (see Figure 4C), our results showed a decreasing trend with increasing $\mathrm{Zn}$ content in the crystalline structure. In other words, we find that the lower the Mn content and crystallite size, the smaller the strain. Since the lattice strain rises from lattice imperfections ${ }^{70}$, one would firstly expect that the size reduction would induce an increase in strain, as observed in a previous work with core@shell NPs synthesized with the same chemical route ${ }^{71}$. In this latter work, increasing shell thickness was leading to an increase in lattice strain ${ }^{71}$. However, we observe here the opposite. Our data suggest that for our NPs, the chemical composition of NPs' core plays a major role in the lattice strain. This may be due to increasing vacancies in the spinel structure due to oxidation. In fact, in Table 1, the samples with Mn-richer ferrite cores show higher oxidation parameters $\delta$ (see Table 1 ). It is mainly due to the strong tendency of $\mathrm{Mn}^{2+}$ to undergo oxidation in our synthesis route. This promotes some vacancies in the crystalline structure to maintain the electroneutrality and therefore may increase the crystalline imperfections in such ferrites. In addition, the strain reduction with increasing $\mathrm{Zn}$ content may also be related to the Jahn-Teller elastic deformation of octahedral sites occupied by $\mathrm{Mn}^{3+}$ cations whose proportion is reduced for $\mathrm{Zn}$-richer ferrites.

We obtain that the lattice parameters of the CS-NPs exhibit a $\mathrm{Zn}$ dependence, which is also described by other researchers ${ }^{72-74}$ and which is commonly attributed to the lower ionic radius value of $\mathrm{Zn}^{2+}$ cations as they replace $\mathrm{Mn}$ cations in the ferrite structure. Moreover, it is possible to infer from Figure 4D that the $\langle a\rangle$ values of our CS-NPs follow the same trend of ICDD data for bulk materials, i.e., it decreases as $\mathrm{Mn}$ ions in the structure are progressively replaced by $\mathrm{Zn}$ ones. Nonetheless, our CS-NPs present lower values than expected. Such differences can be explained by a competition between multifactorial aspects. First, the $\mathrm{Fe}^{3+}$ enrichment and $\mathrm{Zn}^{2+}$ loss in the hydrothermal synthesis, and also the maghemite shell's existence, induce an overall decrease in lattice parameters ${ }^{18}$. Once the structure of these samples is described in a core@shell model, the lattice parameter of the NPs depends on the lattice parameter of both core and shell structures, and a value of $a=0.834 \mathrm{~nm}$ for the maghemite shell contributes to the lower values herein reported. Second, the oxidation of $\mathrm{Mn}^{2+}$ cations into $\mathrm{Mn}^{3+}$ and $\mathrm{Mn}^{4+}$ ones naturally lead to a reduction in the interatomic distances ${ }^{13,59}$. In fact, the oxidation of manganese cations was also reported in other works ${ }^{60-63}$ which investigated mixed ferrite NPs based on $\mathrm{Zn}-\mathrm{Mn}$ synthesized by coprecipitation method. It is important to note that both aspects displace the lattice parameter of the NPs to values below the expected ones (ICDD data) since we are not dealing with stoichiometric samples.

\section{Conclusions}

In this work we found that the incorporation of $\mathrm{Zn}$ atoms into the NPs during the coprecipitation induced a reduction in both NP diameter and ferrite stoichiometric deviation. The former is caused by the nature of $\mathrm{Zn}^{2+}$ cations and the latter, is a consequence of the $\mathrm{Zn}$ loss for the hydrothermal synthesis. The surface treatment step after the coprecipitation promoted the coating of NPs with a superficial layer of maghemite, without provoking changes in the crystalline symmetry of the nanocrystals. After the entire synthetic procedure, the NPs are better described by a core@shell chemical model.

Concerning crystallinity and structure of the CS-NPs, they presented a single phase of spinel-like structure and the lattice parameters do not correspond to the ICDD standard values. This result may be due to the $\mathrm{Fe}^{3+}$ enrichment in both NPs core and shell phases, and may be due the oxidation 
of manganese cations. Finally, we obtained larger lattice strain values for Mn-richer samples, which may be related to more vacancies into the ferrite's structure, thanks to the easy oxidation of $\mathrm{Mn}^{2+}$ cations in our chemical route.

\section{Acknowledgments}

This work was supported by the Brazilian agencies CNPq, CAPES, and FAP/DF. We greatly acknowledge the bilateral program between French-Brazilian universities SU (ex UPMC)/France and UnB/Brazil through the contracts PICS/CNRS n ${ }^{\circ}$ 5939/11, CAPES/COFECUB n ${ }^{\circ} 714 / 11$ and $\mathrm{n}^{\circ} \mathrm{Ph} 959 / 20$. The authors are also greatly indebted to LNLS for the beam-time obtained on the D12A-XRD1 beamline (X-ray diffraction) and to the TEM Platform Faculty of Sciences - Sorbonne Université - SU/France.

\section{References}

1. Johannsen M, Gneveckow U, Eckelt L, Feussner A, Waldöfner $\mathrm{N}$, Scholz R, et al. Clinical hyperthermia of prostate cancer using magnetic nanoparticles: presentation of a new interstitial technique. Int J Hyperthermia. 2005;21(7):637-47. http://dx.doi. org/10.1080/02656730500158360.

2. Calatayud MP, Soler E, Torres TE, Campos-Gonzalez E, Junquera C, Ibarra MR, et al. Cell damage produced by magnetic fluid hyperthermia on microglial BV2 cells. Sci Rep. 2017;7(1):8627. http://dx.doi.org/10.1038/s41598-017-09059-7.

3. Levada K, Omelyanchik A, Rodionova V, Weiskirchen R, Bartneck M. Magnetic-assisted treatment of liver fibrosis. Cells. 2019;8(10):1279. http://dx.doi.org/10.3390/cells8101279.

4. Mitchell MJ, Billingsley MM, Haley RM, Wechsler ME, Peppas NA, Langer R. Engineering precision nanoparticles for drug delivery. Nat Rev Drug Discov. 2021;20(2):101-24. http:// dx.doi.org/10.1038/s41573-020-0090-8.

5. Popescu RC, Savu D, Dorobantu I, Vasile BS, Hosser H, Boldeiu A, et al. Efficient uptake and retention of iron oxide-based nanoparticles in HeLa cells leads to an effective intracellular delivery of doxorubicin. Sci Rep. 2020;10(1):10530. http:// dx.doi.org/10.1038/s41598-020-67207-y.

6. Li J, Hu J, Ma C, Wang Y, Wu C, Huang J, et al. Uptake, translocation and physiological effects of magnetic iron oxide $\left(\gamma-\mathrm{Fe}_{2} \mathrm{O}_{3}\right)$ nanoparticles in corn (Zea mays L.). Chemosphere. 2016;159:326-34. http://dx.doi.org/10.1016/j. chemosphere.2016.05.083.

7. Rui M, Ma C, Hao Y, Guo J, Rui Y, Tang X, et al. Iron oxide nanoparticles as a potential iron fertilizer for peanut (Arachis hypogaea). Front Plant Sci. 2016;7:815. http://dx.doi.org/10.3389/ fpls.2016.00815.

8. Huang X, Zhu-Barker X, Horwath WR, Faeflen SJ, Luo H, Xin $X$, et al. Effect of iron oxide on nitrification in two agricultural soils with different pH. Biogeosciences. 2016;13(19):5609-17. http://dx.doi.org/10.5194/bg-13-5609-2016.

9. Tang SCN, Lo IMC. Magnetic nanoparticles: essential factors for sustainable environmental applications. Water Res. 2013;47(8):261332. http://dx.doi.org/10.1016/j.watres.2013.02.039.

10. Campos AFC, Oliveira HAL, Silva FN, Silva FG, Coppola $\mathrm{P}$, Aquino R, et al. Core-shell bimagnetic nanoadsorbents for hexavalent chromium removal from aqueous solutions. J Hazard Mater. 2018;2019(362):82-91. http://dx.doi.org/10.1016/j. jhazmat.2018.09.008.

11. de Oliveira HAL, Campos AFC, Gomide G, Zhang Y, Ghoshal S. Elaboration of a core@shell bimagnetic nanoadsorbent

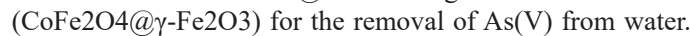
Colloids Surf A Physicochem Eng Asp. 2020;600:125002. http://dx.doi.org/10.1016/j.colsurfa.2020.125002.
12. Ivanets AI, Srivastava V, Roshchina MY, Sillanpää M, Prozorovich VG, Pankov VV. Magnesium ferrite nanoparticles as a magnetic sorbent for the removal of $\mathrm{Mn}^{2+}, \mathrm{Co}^{2+}, \mathrm{Ni}^{2+}$ and $\mathrm{Cu}^{2+}$ from aqueous solution. Ceram Int. 2018;44(8):9097-104. http://dx.doi.org/10.1016/j.ceramint.2018.02.117.

13. Beji Z, Sun M, Smiri LS, Herbst F, Mangeney C, Ammar $\mathrm{S}$. Polyol synthesis of non-stoichiometric Mn-Zn ferrite nanocrystals: structural/microstructural characterization and catalytic application. RSC Advances. 2015;5(80):65010-22. http://dx.doi.org/10.1039/C5RA07562A.

14. Chiang C, Lin K, Hsu P, Lin Y. Synthesis and characterization of magnetic zinc and manganese ferrite catalysts for decomposition of carbon dioxide into methane. Int J Hydrogen Energy. 2017;42(34):22123-37. http://dx.doi.org/10.1016/j. ijhydene.2017.06.033.

15. Zhao L, Lin Z, Ma X, Dong Y. Catalytic activity of different iron oxides : insight from pollutant degradation and hydroxyl radical formation in heterogeneous Fenton-like systems. Chem Eng J. 2018;352(15):343-51. http://dx.doi.org/10.1016/j. cej.2018.07.035.

16. Tholkappiyan R, Vishista K. Influence of lanthanum on the optomagnetic properties of zinc ferrite prepared by combustion method. Physica B. 2014;448:177-83. http://dx.doi.org/10.1016/j. physb.2014.04.022.

17. Coppola P, Silva FG, Gomide G, Paula FLO, Campos AFC, Perzynski R, et al. Hydrothermal synthesis of mixed zinccobalt ferrite nanoparticles: structural and magnetic properties. J Nanopart Res. 2016;18(5):138. http://dx.doi.org/10.1007/ s11051-016-3430-1.

18. Pilati V, Cabreira Gomes R, Gomide G, Coppola P, Silva FG, Paula FLO, et al. Core/shell nanoparticles of non-stoichiometric $\mathrm{Zn}-\mathrm{Mn}$ and $\mathrm{Zn}$-Co ferrites as thermosensitive heat sources for magnetic fluid hyperthermia. J Phys Chem C. 2018;122(5):302838. http://dx.doi.org/10.1021/acs.jpcc.7b11014.

19. Jagadeesha Angadi V, Kubrin SP, Sarychev DA, Matteppanavar S, Rudraswamy B, Liu HL, et al. Low temperature Mössbauer spectroscopic studies on Sm3+ doped Zn-Mn ferrites. J Magn Magn Mater. 2017;441:348-55. http://dx.doi.org/10.1016/j. jmmm.2017.05.080.

20. Kannan YB, Saravanan R, Srinivasan N, Praveena K, Sadhana K. Structural, magnetic, optical, and MEM studies on Coprecipitated $\mathrm{X}_{0} \cdot \mathrm{Zn}_{0} \cdot{ }_{6} \mathrm{Fe}_{2} \mathrm{O}_{4}(\mathrm{X}=\mathrm{Co}, \mathrm{Mn})$ nanoferrite particles. J Supercond Nov Magn. 2017;30(9):2673-82. http://dx.doi. org/10.1007/s10948-017-4081-X.

21. Praveena K, Sadhana K, Liu HL, Maramu N, Himanandini G. Improved microwave absorption properties of $\mathrm{TiO}_{2}$ and $\mathrm{Ni}_{0.53} \mathrm{Cu}_{0.12} \mathrm{Zn}_{0.35} \mathrm{Fe}_{2} \mathrm{O}_{4}$ nanocomposites potential for microwave devices. J Alloys Compd. 2016;681:499-507. http://dx.doi. org/10.1016/j.jallcom.2016.04.190.

22. Berry CC. Progress in functionalization of magnetic nanoparticles for applications in biomedicine. J Phys D Appl Phys. 2009;42(22):224003. http://dx.doi.org/10.1088/0022$3727 / 42 / 22 / 224003$.

23. Praveena K, Matteppanavar S, Liu HL, Sadhana K. Effect of pH on electrical and magnetic properties of $\mathrm{Al}_{3} \mathrm{Fe}_{5} \mathrm{O}_{12}$ nanoparticles. J Mater Sci Mater Electron. 2017;28(5):4179-91. http://dx.doi. org/10.1007/s10854-016-6038-4.

24. Praveena K, Sadhana K, Matteppanavar S, Liu HL. Effect of sintering temperature on the structural, dielectric and magnetic properties of $\mathrm{Ni}_{0.4} \mathrm{Zn}_{0.2} \mathrm{Mn}_{0.4} \mathrm{Fe}_{2} \mathrm{O}_{4}$ potential for radar absorbing. J Magn Magn Mater. 2017;423:343-52. http://dx.doi.org/10.1016/j. jmmm.2016.09.129.

25. Omelyanchik A, Levada K, Pshenichnikov S, Abdolrahim M, Baricic M, Kapitunova A, et al. Green synthesis of Co-Zn spinel ferrite nanoparticles: magnetic and intrinsic antimicrobial properties. Materials. 2020;13(21):5014. http://dx.doi.org/10.3390/ ma13215014. 
26. Mameli V, Musinu A, Ardu A, Ennas G, Peddis D, Niznansky $\mathrm{D}$, et al. Studying the effect of $\mathrm{Zn}$-substitution on the magnetic and hyperthermic properties of cobalt ferrite nanoparticles. Nanoscale. 2016;8(19):10124-37. http://dx.doi.org/10.1039/ C6NR01303A.

27. Praveena K, Sadhana K, Liu HL, Murthy SR. Effect of Zn substitution on structural, dielectric and magnetic properties of nanocrystalline $\mathrm{Co}_{1-\mathrm{x}} \mathrm{Zn}_{\mathrm{x}} \mathrm{Fe}_{2} \mathrm{O}_{4}$ for potential high density recording media. J Mater Sci Mater Electron. 2016;27(12):12680-90. http://dx.doi.org/10.1007/s10854-016-5402-8.

28. Sadhana K, Murthy SR, Praveena K. Effect of $\mathrm{Sm}^{3+}$ on dielectric and magnetic properties of $\mathrm{Y}_{3} \mathrm{Fe}_{5} \mathrm{O}_{12}$ nanoparticles. J Mater Sci Mater Electron. 2014;25(11):5130-6. http://dx.doi.org/10.1007/ s10854-014-2282-7.

29. Hölscher J, Petrecca M, Albino M, Garbus PG, Saura-Múzquiz $\mathrm{M}$, Sangregorio $\mathrm{C}$, et al. Magnetic property enhancement of spinel $\mathrm{Mn}-\mathrm{Zn}$ ferrite through atomic structure control. Inorg Chem. 2020;59(15):11184-92. http://dx.doi.org/10.1021/acs. inorgchem.0c01809.

30. Kannan YB, Saravanan R, Srinivasan N, Praveena K, Sadhana $\mathrm{K}$. Synthesis and characterization of some ferrite nanoparticles prepared by co-precipitation method. J Mater Sci Mater Electron. 2016;27(11):12000-8. http://dx.doi.org/10.1007/s10854-0165347-y.

31. Cheng HW, Li J, Wong S, Zhong CJ. Assessment of aggregative growth of MnZn ferrite nanoparticles. Nanoscale. 2016;8(46):1935967. http://dx.doi.org/10.1039/C6NR06819G.

32. Barrera G, Coisson M, Celegato F, Raghuvanshi S, Mazaleyrat F, Kane SN, et al. Cation distribution effect on static and dynamic magnetic properties of $\mathrm{Co}_{1-\mathrm{x}} \mathrm{Zn}_{\mathrm{x}} \mathrm{Fe}_{2} \mathrm{O}_{4}$ ferrite powders. J Magn Magn Mater. 2018;456:372-80. http://dx.doi.org/10.1016/j. jmmm.2018.02.072.

33. Thakur P, Chahar D, Taneja S, Bhalla N, Thakur A. A review on MnZn ferrites: synthesis, characterization and applications. Ceram Int. 2020;46(10):15740-63. http://dx.doi.org/10.1016/j. ceramint.2020.03.287.

34. Rath C, Sahu KK, Anand S, Date SK, Mishra NC, Das RP. Preparation and characterization of nanosize $\mathrm{Mn}-\mathrm{Zn}$ ferrite. J Magn Magn Mater. 1999;202(1):77-84. http://dx.doi.org/10.1016/ S0304-8853(99)00217-6.

35. Arulmurugan R, Vaidyanathan $\mathrm{G}$, Sendhilnathan $\mathrm{S}$, Jeyadevan B. Thermomagnetic properties of $\mathrm{Co}_{1-\mathrm{x}} \mathrm{Zn}_{\mathrm{x}} \mathrm{Fe}_{2} \mathrm{O}_{4}(\mathrm{x}=0.1-0.5)$ nanoparticles. J Magn Magn Mater. 2006;303(1):131-7. http:// dx.doi.org/10.1016/j.jmmm.2005.10.237.

36. Xuan Y, Li Q, Yang G. Synthesis and magnetic properties of Mn-Zn ferrite nanoparticles. J Magn Magn Mater. 2007;312(2):464-9. http://dx.doi.org/10.1016/j.jmmm.2006.11.200.

37. Lin M, Huang J, Sha M. Recent advances in nanosized Mn$\mathrm{Zn}$ ferrite magnetic fluid hyperthermia for cancer treatment. J Nanosci Nanotechnol. 2014;14(1):792-802. http://dx.doi. org/10.1166/jnn.2014.9135.

38. Bhardwaj A, Parekh K, Jain N. In vitro hyperthermic effect of magnetic fluid on cervical and breast cancer cells. Sci Rep. 2020;10(1):15249. http://dx.doi.org/10.1038/s41598-02071552-3.

39. Calatayud MP, Sanz B, Raffa V, Riggio C, Ibarra MR, Goya GF. The effect of surface charge of functionalized $\mathrm{Fe} 3 \mathrm{O} 4$ nanoparticles on protein adsorption and cell uptake. Biomaterials. 2014;35(24):6389-99. http://dx.doi.org/10.1016/j. biomaterials.2014.04.009.

40. Yang J, Fan L, Xu Y, Xia J. Iron oxide nanoparticles with different polymer coatings for photothermal therapy. J Nanopart Res. 2017;19(10):333. http://dx.doi.org/10.1007/s11051-0174031-3.

41. Salehipour M, Rezaei S, Mosafer J, Pakdin-Parizi Z, Motaharian A, Mogharabi-Manzari M. Recent advances in polymer-coated iron oxide nanoparticles as magnetic resonance imaging contrast agents. J Nanopart Res. 2021;23(2):48. http://dx.doi.org/10.1007/ s11051-021-05156-x.

42. Lee J-H, Jang J-T, Choi J-S, Moon SH, Noh S-H, Kim J-W, et al. Exchange-coupled magnetic nanoparticles for efficient heat induction. Nat Nanotechnol. 2011;6(7):418-22. http://dx.doi. org/10.1038/nnano.2011.95.

43. Sanna Angotzi M, Mameli V, Cara C, Musinu A, Sangregorio C, Niznansky D, et al. Coupled hard-soft spinel ferrite-based core-shell nanoarchitectures: magnetic properties and heating abilities. Nanoscale Adv. 2020;2(8):3191-201. http://dx.doi. org/10.1039/D0NA00134A.

44. Lavorato GC, Das R, Xing Y, Robles J, Litterst FJ, BaggioSaitovitch E, et al. Origin and shell-driven optimization of the heating power in core/shell bimagnetic nanoparticles. ACS Appl Nano Mater. 2020;3(2):1755-65. http://dx.doi.org/10.1021/ acsanm.9b02449.

45. Silva FG, Depeyrot J, Raikher YL, Stepanov VI, Poperechny IS, Aquino R, et al. Exchange-bias and magnetic anisotropy fields in core-shell ferrite nanoparticles. Sci Rep. 2021;11(1):5474. http://dx.doi.org/10.1038/s41598-021-84843-0.

46. Tourinho FA, Franck R, Massart R. Aqueous ferrofluids based on manganese and cobalt ferrites. J Mater Sci. 1990;25(7):324954. http://dx.doi.org/10.1007/BF00587682.

47. Massart R. Preparation of aqueous magnetic liquids in alkaline and acidic media. IEEE Trans Magn. 1981;17(2):1247-8. http:// dx.doi.org/10.1109/TMAG.1981.1061188.

48. Sousa MH, Tourinho FA, Jose G, Lara MCFL. New electric double-layered magnetic fluids based on copper, nickel, and zinc ferrite nanostructures. J Phys Chem B. 2001;105(6):116875. http://dx.doi.org/10.1021/jp0039161.

49. Gomes JDA, Sousa MH, Tourinho FA, Aquino R, Silva GJ, Depeyrot J, et al. Synthesis of core-shell ferrite nanoparticles for ferrofluids: chemical and magnetic analysis. J Phys Chem C. 2008;112(16):6220-7. http://dx.doi.org/10.1021/jp7097608.

50. Cabreira-Gomes RG, Silva F, Aquino R, Bonville $\mathrm{P}$, Tourinho FA, Perzynski R, et al. Exchange bias of $\mathrm{MnFe}_{2} \mathrm{O}_{4} @ \gamma-\mathrm{Fe}_{2} \mathrm{O}_{3}$ and $\mathrm{CoFe}_{2} \mathrm{O}_{4} @ \gamma-\mathrm{Fe}_{2} \mathrm{O}_{3}$ core/shell nanoparticles. J Magn Magn Mater. 2014;368:409-14. http://dx.doi.org/10.1016/j. jmmm.2014.03.003.

51. Lavorato GC, Das R, Alonso Masa J, Phan MH, Srikanth H. Hybrid magnetic nanoparticles as efficient nanoheaters in biomedical applications. Nanoscale Adv. 2021;3(4):867-88. http://dx.doi.org/10.1039/D0NA00828A.

52. Pilati V, Gomide G, Gomes RC, Goya GF, Depeyrot J. Colloidal stability and concentration effects on nanoparticle heat delivery for magnetic fluid hyperthermia. Langmuir. 2021;37(3):112940. http://dx.doi.org/10.1021/acs.langmuir.0c03052.

53. Campos AFC, Tourinho FA, Silva GJ, Lara MCFL, Depeyrot J. Nanoparticles superficial density of charge in electric doublelayered magnetic fluid: a conductimetric and potentiometric approach. Eur Phys J E. 2001;6(1):29-35. http://dx.doi. org $/ 10.1007 / \mathrm{s} 101890170025$.

54. Williamson GK, Hall WH. X-ray line broadening from filed aluminium and wolfram. Acta Metall. 1953;1(1):22-31. http:// dx.doi.org/10.1016/0001-6160(53)90006-6.

55. Suryanarayana C, Norton GM. X-ray diffaction: a practical approach. Boston: Springer; 1998. 273 p.

56. Zamkovskaya A, Maksimova E, Nauhatsky I. Size-strain linebroadening analysis of the calcite-type borates $\mathrm{ABO}_{3}(\mathrm{~A}=\mathrm{Fe}$, In, Ga). J Phys Conf Ser. 2018;1135:012020. http://dx.doi. org/10.1088/1742-6596/1135/1/012020.

57. Bennet J, Tholkappiyan R, Vishista K, Jaya NV, Hamed F. Attestation in self-propagating combustion approach of spinel $\mathrm{AFe}_{2} \mathrm{O}_{4}(\mathrm{~A}=\mathrm{Co}, \mathrm{Mg}$ and $\mathrm{Mn})$ complexes bearing mixed oxidation states: magnetostructural properties. Appl Surf Sci. 2016;383:113-25. http://dx.doi.org/10.1016/j.apsusc.2016.04.177.

58. Zhang L, Holt CMB, Luber EJ, Olsen BC, Wang H, Danaie $\mathrm{M}$, et al. High rate electrochemical capacitors from three- 
dimensional arrays of vanadium nitride functionalized carbon nanotubes. J Phys Chem C. 2011;115(49):24381-93. http:// dx.doi.org/10.1021/jp205052f.

59. Martins FH, Silva FG, Paula FLO, Gomes JDA, Aquino R, Mestnik-Filho J, et al. Local structure of core-shell $\mathrm{MnFe}_{2} \mathrm{O}_{4}+\mathrm{d}$ Based nanocrystals: cation distribution and valence states of manganese ions. J Phys Chem C. 2017;121(16):8982-91. http:// dx.doi.org/10.1021/acs.jpcc.6b09274.

60. Wiriya N, Bootchanont A, Maensiri S, Swatsitang E. Microelectronic engineering magnetic properties of $\mathrm{Zn}_{1-\mathrm{x}} \mathrm{Mn}$ $\mathrm{xFe}_{2} \mathrm{O}_{4}$ nanoparticles prepared by hydrothermal method. Microelectron Eng. 2014;126:1-8. http://dx.doi.org/10.1016/j. mee.2014.03.044.

61. Moro Y, Katayanagi H, Kimura S, Shigeoka D, Hiroki T, Mashino $\mathrm{T}$, et al. Size control of $\mathrm{Mn}-\mathrm{Zn}$ ferrite nanoparticles and their XAFS spectra. Surf Interface Anal. 2010;42(10-11):1655-8. http://dx.doi.org/10.1002/sia.3621.

62. Makovec D, Kodre A, Arčon I, Drofenik M. Structure of manganese zinc ferrite spinel nanoparticles prepared with co-precipitation in reversed microemulsions. J Nanopart Res. 2009;11(5):1145-58. http://dx.doi.org/10.1007/s11051-0089510-0.

63. Kodre A, Ar I, Pade J, Makovec D. An expanded EXAFS model of Mn, Zn, and Fe spinel nanoparticles. Acta Chim Slov. 2008;55:125-31.

64. Saratovsky I, Wightman PG, Pastén PA, Gaillard JF, Poeppelmeier KR. Manganese oxides: parallels between abiotic and biotic structures. J Am Chem Soc. 2006;128(34):11188-98. http:// dx.doi.org/10.1021/ja062097g.

65. Paula FLO. SAXS Analysis of magnetic field influence on magnetic nanoparticle clusters. Condensed Matter. 2019;4(2):55. http://dx.doi.org/10.3390/condmat4020055.

66. Auzans E, Zins D, Blums E, Massart R. Synthesis and properties of Mn-Zn ferrite ferrofluids. J Mater Sci. 1999;34(6):1253-60. http://dx.doi.org/10.1023/A:1004525410324.
67. Gnanaprakash G, Philip J, Raj B. Effect of divalent metal hydroxide solubility product on the size of ferrite nanoparticles. Mater Lett. 2007;61(23-24):4545-8. http://dx.doi.org/10.1016/j. matlet.2007.02.048.

68. Stumm W. Chemistry of the solid-water interface: processes at the mineral-water and particle-water interface in natural systems. New York. John Wiley \& Sons; 1992. 448 p.

69. Rath C, Anand S, Das RP, Sahu KK, Kulkarni SD, Date SK, et al. Dependence on cation distribution of particle size, lattice parameter, and magnetic properties in nanosize Mn-Zn ferrite. J Appl Phys. 2002;91(4):2211-5. http://dx.doi. org/10.1063/1.1432474.

70. Zak AK, Majid WHA, Abrishami ME, Youse R. X-ray analysis of $\mathrm{ZnO}$ nanoparticles by Williamson e Hall and size e strain plot methods. Solid State Sci. 2011;13(1):251-6. http://dx.doi. org/10.1016/j.solidstatesciences.2010.11.024.

71. Gomes JA, Azevedo GM, Depeyrot J, Mestnik-Filho J, Paula FLO, Tourinho FA, et al. Structural, chemical, and magnetic investigations of core-shell zinc ferrite nanoparticles. J Phys Chem C. 2012;116(45):24281-91. http://dx.doi.org/10.1021/ jp3055069.

72. Arulmurugan R, Vaidyanathan G, Sendhilnathan S, Jeyadevan B. $\mathrm{Mn}-\mathrm{Zn}$ ferrite nanoparticles for ferrofluid preparation: study on thermal-magnetic properties. J Magn Magn Mater. 2006;298(2):83-94. http://dx.doi.org/10.1016/j.jmmm.2005.03.002.

73. Abbas T, Khan Y, Ahmad M, Anwar S. X-ray diffraction of the cation distribution in the Mn-Zn-ferrites. Solid State Commun. 1992;82(9):701-3. http://dx.doi.org/10.1016/00381098(92)90064-G.

74. Hessien MM, Rashad MM, El-Barawy K, Ibrahim IA. Influence of manganese substitution and annealing temperature on the formation, microstructure and magnetic properties of $\mathrm{Mn}-\mathrm{Zn}$ ferrites. J Magn Magn Mater. 2008;320(9):1615-21. http:// dx.doi.org/10.1016/j.jmmm.2008.01.025. 